\title{
Integrated Geo-information System for the Development of Low Carbon Eco-city in China Urban Context
}

\author{
Biao Liu, Jinyeu Tsou, Mingchun Chao and Wen Fu \\ Center for Housing Innovations, Chinese University of Hong Kong, Hong Kong 999077, China
}

\begin{abstract}
Nowadays, cities are the main living environment of human beings. Rapid urbanization is associated with a variety of issues: population explosion, urban heat island effect, greenhouse gases emissions, energy crisis, climate change and so on. To deal with the challenges from the huge energy consumption and GHGs (greenhouse gases) emission, more and more attention has been paid to low carbon eco-city in China. In this research, the whole process is linked by low carbon eco-city development. High-resolution thermal IR (infrared) satellite remote-sensing is introduced to land use and urban heat island monitoring to meet the requirement of higher accuracy. GIS (geo-information science) technology provides a framework for collecting, processing, managing, analyzing and sharing spatial and temporal data. It has been used in spatial and temporal database management and analysis in low carbon eco-city study. The integrated geo-information system proposed in this research, which will be introduced to various government agencies in China, could enrich the concepts and means for the construction of low carbon eco-city.
\end{abstract}

Key words: GIS, low carbon eco-city, China.

\section{Introduction}

Nowadays, cities are the main living environment of human beings. Urban population accounted for less than $15 \%$ of total population in world in 100 years ago, while now more than $50 \%$ populations are living in cities [1]. Rapid urbanization is associated with a variety of issues: population explosion, urban heat island effect, greenhouse gas emissions, energy crisis, climate change and so on.

With the crisis raised by rapid urbanization and urban housing development, more and more attention has been paid to the concept of low carbon eco-city, which aims to build suitable living environment, emphasizing on energy consumption and GHGs (greenhouse gases) emission, especially carbon emissions. Low carbon was first proposed in White Paper titled "Energy White Paper, Our Energy Future: Creating a Low Carbon Economy" in UK [2]. Eco-city, also known as ecological city, was put forward in 1970s, in the MAB (Man and Biosphere program) by UNESCO (United Nations Educational,

Corresponding author: Biao Liu, Dr., research field: geo-information science. E-mail: liubiao@cuhk.edu.hk.
Scientific and Cultural Organization). Cities are planned or renewed with concern of ecological principles to be more livable. Thus, energy conservation, green constructions, and climate change initiatives are the key issues for low carbon eco-city.

To deal with the challenges from the huge energy consumption and GHGs emission, China starts to promote low carbon eco-city development strategy. According to China-GBC (China Green Building Council) statistics, more than 260 cities have proposed a program of building low carbon eco-city in 2011 while only 110 cities in 2010. In China, urban heat island is the most typical crisis, which makes urban thermal environment draw a widely attention. And, it is generally considered that urban thermal environment is related to land use [3]. Survey and statistical analysis are the most commonly used methods in previous studies [4-5]. In the past years, a large number of techniques, which are related to environmental simulation, environmental monitoring and spatial information science, are adopted to study urban habitant heat effect and land use change to support planning decision [6-9]. However, less 
attention has been paid to how to integrate these techniques and make them practical for the development of low carbon eco-city in multi-scale.

In this research, the whole process is linked by this main purpose. High-resolution thermal IR satellite remote-sensing is introduced to land use and urban heat island monitoring to meet the requirement of higher accuracy. GIS technology provides a framework for collecting, processing, managing, analyzing and sharing spatial and temporal data. It has been used in spatial and temporal database management in low carbon eco-city study. Based on our previous research, this research is divided into the following two components:

(1) Thermal infrared system

A thermal infrared system is proposed to conduct the real-time monitoring, qualitative analysis and simulation for urban habitant heat effect in multi-level;

(2) GIS (geo-information science)-based techniques for low carbon eco-city

Geo-database management system, geo-visualization and spatial and temporal analysis and prediction for urban land use change are introduced to the study of low carbon eco-city in this part.

\section{Methodology}

\subsection{Thermal Infrared System}

Multi-scale and multi-level characteristics of the urban-heat island have been studied in GIS (geographic information system), RS (remote sensing) and other research fields. Thermal infrared, which plays a key role in thermal characteristic analysis for low carbon eco-city in this research, is a new and important technology applied in this China urban context. As all know, there are many climate zones in China. Low carbon eco-city design must use different methods in different climate zones. For instance, the design focuses on leakage of heating in cold climate zones. It focuses on heat in tropics and subtropics. In
China, subtropics contain many big cities, such as Guangzhou, Hong Kong, Shanghai and so on. They all face the urban heat island effect and urbanization problem. Thus, using thermal infrared to decrease low carbon eco-city heat in subtropics is meaningful in China.

Thermal infrared is a finest, easiest and quickest method to detect object's heat. Moreover, an infrared camera could show the energy loss and temperature difference in detail. Thermal infrared technique is an ideal tool to capture thermal data in time. After data collection, it is very useful to capture the construction material temperature and monitor energy consumption by relative software. Small-scale infrared detection is suggested to detect the heat sources in order to stand out the 3D, multi-level, multi-object and nonlinear features in this study.

Based on the research conducted by CHI (Center of Housing Innovations) and Shanghai Institute of Technical Physics of the Chinese Academy of Sciences, a new thermal infrared system was developed. The research is divided into two scales, community scale and building scale. Community scale includes green space monitoring, water vapor evaporation monitoring and thermal comfort environment monitoring. Building scale includes water leakage, cold air infiltration, and material thermal characteristic.

There are three phases in the study. It includes policy study, data collection and software analysis.

\subsubsection{Policy Study}

Policy is the main part of a city design. They collect relative policy about low carbon eco-city in subtropics. For example, BCA Green Mark Certification Standard for New Buildings, BEAM Plus for New Buildings, and China Three Star. The important points have been fond from the green policy. The points must be related to the urban heat, as green ratio, permeable ground, material, vertical green, etc..

2.1.2 Data Collection

After relative policy study, portable thermal 
infrared camera is used to capture the data (Fig. 1). The data are related to the important points which are studied in former phase. At the same time, they collect field temperature, material, measuring time, and position measured by GPS (global positioning system).

The objectives are divided into two parts, community scale and building scale. Thermal infrared can be used in low carbon eco-city study. The details are shown in Table 1.

\subsubsection{Software Analysis}

The captured data is put into software, analyzed the data and concluded the solution for the low carbon eco-city design. This software has been developed by CHI.

\subsection{GIS (Geo-information Science)-Based Techniques for Low Carbon Eco-city}

\subsubsection{Geo-database Management and} Geo-visualization System

In this part, the authors have to deal with massive spatial and temporal data collection, management and sharing. Geo-database management system, geo-visualization and spatial and temporal data analysis are introduced to the study of low carbon eco-city. In previous study, geo-database is the most used GIS technology. A database with spatial and temporal index is built for data access and management, such as the pollution sources, urban buildings and transport networks. Geo-visualization is a supporting tool for spatial and temporal data analysis, especially exploring data analysis. A thematic map is the most common visual representation for geographic information. For example, a haze information inquiry system was established to query, represent, track and simulate the haze trajectory, therefore, the authors can analyze the source and movement of aerosol by this system. Most of functions of this part are under construction.

2.2.2 Spatial and Temporal Analysis and Prediction of Land Use Change

Secondly, spatial and temporal analysis and prediction of land use change, which can accurately perform scenario-based simulation and prediction for urban development, is also an effective technique to evaluate the related policy for low carbon eco-city. It could benefit urban planners and policy makers to have better understanding of the land use change in a
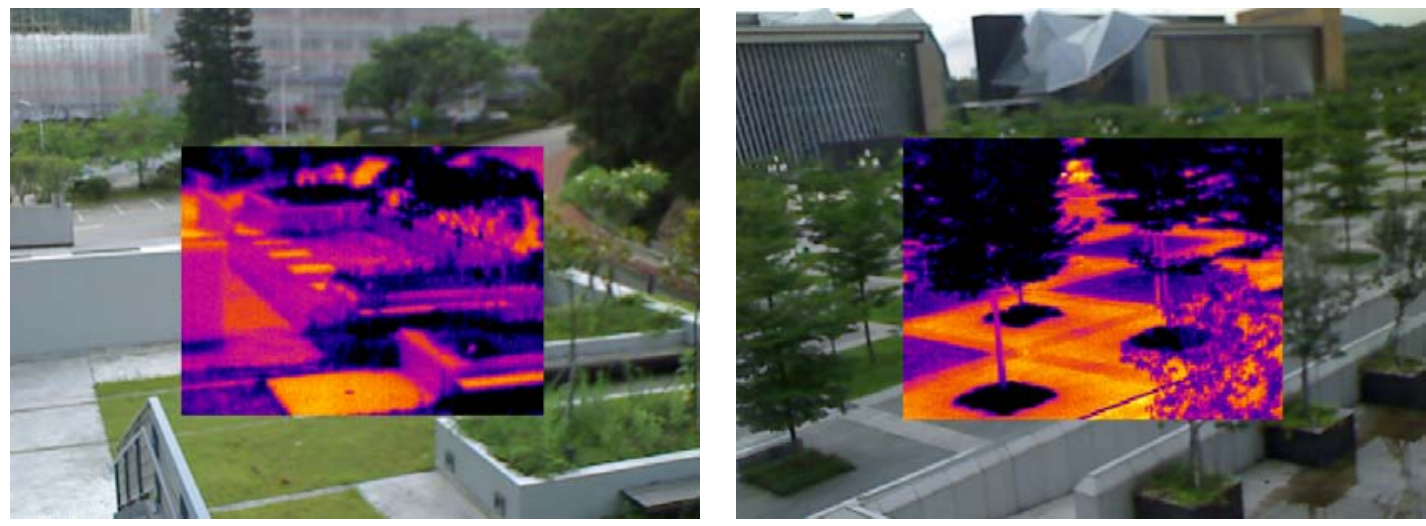

Fig. 1 Data-permeable ground, material thermal characteristic.

Table 1 Study area in different scales of thermal infrared.

\begin{tabular}{ll}
\hline Community scale & Building scale \\
\hline -Green space monitoring & -Heat loss \\
-Water vapor evaporation monitoring & -Water leakage \\
-Thermal comfort environment monitoring & -Cold air infiltration \\
& -Electrical service problem \\
\hline
\end{tabular}


spatial and temporal framework, make more precise projections of land use, and also to help them generate scientific low carbon eco-plans.

Previous land use change studies have demonstrated different levels of success in their specific applications, however, there are still several problems that need to be addressed: First of all, the modeling methodology should account for multi-class land use change (e.g., residential to commercial and industrial, etc. in support of urban redevelopment studies) rather than binary changes only (e.g., rural to urban in support of urban sprawl studies); Secondly, each land parcel will have its own individual effect. If land type is urban, the probability of land use change on this cell will be lower than rural. For such situation, more detail analysis about the individual effect in the land use change modeling should be incorporated; Thirdly, it is common that substantial amounts of spatial variables and spatial land-use data have the tendency to be dependent, a phenomenon known as spatial autocorrelation [10]. However, in working with the spatial temporal data, specific approaches should be considered to incorporate both spatial and temporal autocorrelation; Fourthly, due to different administrative, political or other contextual issues, the relationships between land use change and driver factors in different locations and time might be intrinsically different. Hence, spatial and temporal non-stationarity, which means different relationships exist at different locations and time, should be considered in land use change analysis; Finally, all the problems mentioned above are not separated (e.g., spatial and temporal non-stationarity can be partly considered in spatial and temporal autocorrelation). Thus, the most important item is that land use change modeling should be capable of generalizing a series of changes in spatial and temporal framework into a unified model for better projection of land use distribution with consideration of multi-class land use type, individual effect, spatial and temporal autocorrelations and spatial and temporal non-stationarity.

This part constructs a novel statistical model to support spatial and temporal analysis and prediction of land use change: Firstly, panel model which can consider the individual effect of each land parcel is introduced to land use change modeling. Based upon the panel data analysis framework, the proposed model (spatial and temporal panel logistic model), which incorporates the covariance of a cell to other cells into the model formulation to involve spatial and temporal autocorrelation, considers the random effects of a land use cell with reference to both space and time and builds up the relationship between various factors and land use patterns over time; Secondly, in order to incorporate spatial and temporal non-stationarity, the GWR (geographically weighted regression) model that can deal with spatial non-stationarity was extended to GTWR (geographically and temporal weighted regression); Finally, the two models mentioned above have been combined together. Notably, the proposed model integrates individual effect, spatial and temporal autocorrelation with spatial and temporal non-stationarity in the same framework. In the model proposed by the authors, the accuracy has been improved significantly.

\section{Conclusions}

The introduction and development of these techniques represents a paradigm shift for low carbon eco-city construction field. Low carbon eco-city should become to be associated with cutting edge technology. Eco-city not only belongs to the traditional space design issue, but also should apply technologies, as remote sensing and GIS. Planner and designer should use an interdisciplinary method to create a low carbon eco-city.

The integrated geo-information system proposed in our research, which will be introduced to various government agencies in China, could enrich the concepts and means for the construction of low carbon 
eco-city. It is also our intent to transfer these technologies and development concepts to academia and practice in China. More techniques for the development of low carbon eco-city will be studied and integrated in our research in the future.

\section{References}

[1] United Nations Economic and Social Council, World Demographic Trends, Report of the Secretary-General, UN, 2009.

[2] UK Government, Energy White Paper, Our Energy Future: Creating a Low Carbon Economy, UK, 2003.

[3] G. Huang, W. Zhou, M.L. Cadenasso, Is everyone hot in the city? Spatial pattern of land surface temperatures, land cover and neighborhood socioeconomic characteristics in Baltimore, MD, Journal of Environmental Management 92 (7) (2011) 1753-1759.

[4] P. Barla, L.F. Miranda-Moreno, M. Lee-Gosselin, Urban travel $\mathrm{CO}_{2}$ emissions and land use: A case study for Quebec City, Transportation Research Part D: Transport and Environment 16 (6) (2011) 423-428.
[5] Y. Chen, X. Li, Y. Zheng, Y. Guan, X. Liu, Estimating the relationship between urban forms and energy consumption: A case study in the Pearl River Delta, 2005-2008, Landscape and Urban Planning 102 (1) (2011) 33-42.

[6] B. Dave, G. Schmitt, Information systems for spatial data, Automation in Construction 4 (1) (1995) 17-28.

[7] M.G. Salim, Selection of groundwater sites in Egypt, using geographic information systems, for desalination by solar energy in order to reduce greenhouse gases, Journal of Advanced Research 3 (1) (2012) 11-19.

[8] H. Merbitz, M. Buttstädt, S. Michael, W. Dott, C. Schneider, GIS-based identification of spatial variables enhancing heat and poor air quality in urban areas, Applied Geography 33 (2012) 94-106.

[9] A.P.D. Turetta, M.L. Mendonca-Santos, L.H.C. Anjos, R.L.L. Berbara, Spatial-Temporal Changes in Land Cover, Soil Properties and Carbon Stocks in Rio de Janeiro, Digital Soil Mapping with Limited Data, Springer Netherlands, Netherlands, 2008, pp. 261-271.

[10] P. Legendre, M.J. Fortin, Spatial pattern and ecological analysis, Vegetatio 80 (1989) 107-138. 